\title{
Preoperative EEG predicts memory and selective cognitive functions after temporal lobe surgery
}

Arja Tuunainen, Unto Nousiainen, Heleena Hurskainen, Esa Leinonen, Antero Pilke, Esa Mervaala, Matti Vapalahti, Juhani Partanen, Paavo Riekkinen

\begin{abstract}
Preoperative and postoperative cognitive and memory functions, psychiatric outcome, and EEGs were evaluated in 32 epileptic patients who underwent temporal lobe surgery. The presence and location of preoperative slow wave focus in routine EEG predicted memory functions of the non-resected side after surgery. Neuropsychological tests of the function of the frontal lobes also showed improvement. Moreover, psychiatric ratings showed that seizure free patients had significantly less affective symptoms postoperatively than those who were still exhibiting seizures. After temporal lobectomies, successful outcome in postoperative memory functions can be achieved in patients with unilateral slow wave activity in preoperative EEGs. This study suggests a new role for routine EEG in preoperative evaluation of patients with temporal lobe epilepsy.
\end{abstract}

$(\mathcal{F}$ Neurol Neurosurg Psychiatry 1995;58:674-680)

Keywords: electroencephalography; epilepsy; temporal lobe surgery; memory

Unilateral epileptic focus of the temporal lobe on EEG predicts the most successful outcome in patients with surgery for temporal lobe epilepsy. ${ }^{12}$ Bitemporal interictal discharges themselves are not considered to be a poor prognostic sign. ${ }^{34}$ In these patients, however, the results of surgical treatment tend to be less favourable than in those with a well defined and unilateral epileptic focus on EEG. ${ }^{5}$ Patients with bilateral epileptiform EEG findings usually also exhibit bilateral non-epileptiform abnormalities in their EEGs. The focal slow wave activity in preoperative EEG has been studied less, and its value in predicting postoperative outcome is virtually unknown.

Neuropsychological tests usually show material specific deficits after temporal lobe surgery; temporal lobectomy on the side dominant for speech (usually left) impairs the learning and retention of verbal information, whereas temporal lobectomy on the nonspeech side (usually right) impairs visual memory. ${ }^{6-9}$ On the other hand, the memory functions of the non-resected side often show slight improvement after surgery. ${ }^{78}$ Improvement has been related to the location of epileptiform EEG findings; in studies of patients with bitemporal abnormalities using depth electrodes, the delayed memory scores have been lower preoperatively and postoperatively compared with the results for patients with purely unilateral findings. ${ }^{9}$ In our study, we hypothesised that the location of slow wave activity might also reflect disturbance in memory functions.

Most epilepsy centres perform psychiatric examinations of patients undergoing preoperative evaluations for epilepsy surgery. Less than half of these centres, however, use organised postoperative psychiatric follow up. ${ }^{10}$ In each patient, the comparison during the follow up is more reliable with standardised rating scales, as the psychiatric status can also be expressed in numerical form. The standardisation of these evaluation protocols is recommended.

The relation of neuropsychological variables to EEG after surgery for epilepsy is poorly understood. It is not known whether the presence and location of preoperative non-epileptiform EEG abnormalities predict cognitive outcome in patients with temporal lobe epilepsy. Thus the aim of this study was to evaluate preoperative and postoperative neuropsychological and psychiatric variables in relation to EEG and clinical outcome in patients referred for temporal lobe surgery. We wanted to determine whether it would be possible to predict postoperative neuropsychological or psychiatric changes based on preoperative routine EEG findings.

\section{Materials and methods}

PATIENTS

Thirty two consecutive patients with epilepsy (12 men, 20 women) were studied, all of whom underwent presurgical evaluation for temporal lobe surgery at Vaajasalo Hospital. These patients had intractable complex partial seizures with or without secondary generalisation. The mean age of the patients at the time of surgery was 36 (range 17-54) years, and the mean duration of epilepsy 25 (range $8-42$ ) years. The mean seizure frequency was 14 (range 2-75) per month. Their mean education period was nine (range 6-15) years. Temporal lobectomies (14 left, 18 right) were performed at the Department of Neurosurgery in Kuopio University Hospital between December 1988 and April 1991. Five additional patients were excluded from our study due to reoperation, and one more patient was dropped from the follow up. Briefly, our study protocol, which has been described elsewhere, ${ }^{11}$ consisted of detailed 
medical history and clinical examination of the patients, laboratory tests, including serum concentrations of antiepileptic drugs, and neurophysiological, neuropsychological, neuroradiological, and psychiatric evaluation. Withdrawal of antiepileptic medication was used to provoke seizures for 16 channel intensive videomonitoring, and depth electrodes were used for four patients. Neither CT of the head nor MRI showed any neoplastic lesions. During the postoperative follow up, antiepileptic medication was kept constant except in one patient, who was treated with carbamazepine monotherapy after discontinuation of phenytoin, and in two patients whose carbamazepine and $\gamma$ vinyl-GABA dosages were reduced slightly. The preoperative examinations were usually started six months to a year before surgery.

SURGICAL PROCEDURE

Tailored anterior temporal lobectomies with amygdalectomy and hippocampectomy were performed by microsurgery with video recording. During every operation, there was 16 channel electrocorticography (ECoG) with two acute depth electrodes inserted into the amygdala and the hippocampus to help determine the zone of epileptiform activity and thus the extent of the resection. The resection included mesial temporal structures (amygdala, anterior hippocampus, and part of the hippocampal gyrus) and the region of the temporal neocortex that showed epileptiform activity during the ECoG. The spikes were activated by intravenous injections of methohexital (Brietal ${ }^{\circledR}$ (40 mg bolus)) both before and after the resection. The patients were operated on under balanced general anaesthesia, which was lightened during the ECoG. In cases with residual epileptiform activity during the postresection ECoG, the operation was further extended if surgically possible. Neocortical resections did not extend more than $4.5 \mathrm{~cm}$ from the temporal tip on the dominant side and $5.5 \mathrm{~cm}$ to $6.0 \mathrm{~cm}$ on the non-dominant side.

\section{OUTCOME}

Surgical outcome was analysed with respect to clinical seizures and was determined according to the guidelines reported by Engel. ${ }^{12}$ For this study, at follow up the patients were classified into two categories: seizure free, which consisted of patients who were completely seizure free, exhibited auras only, or reported atypical generalised convulsion with antiepileptic withdrawal (class I), and not seizure free, which consisted of patients with rare seizures, worthwhile improvement, or no worthwhile improvement (classes II-IV). In this study, the duration of the follow up was one year. The classification of Engel is applied mainly to a postoperative evaluation of at least two years. Thus subclass Ic (some seizures after surgery, but then seizure free for at least two years) could not be assessed; and there might be patients who after the second postoperative year could be raised to class Ic (the seizure free category).
ROUTINE EEG

Routine EEGs were recorded under optimal conditions by 21 channel Mingograf (Siemens, Germany) with silver/silver chloride disc electrodes in the international 10-20 system. Several bipolar and common average monopolar montages were used in each recording. Sphenoidal electrodes ${ }^{13}$ were used both preoperatively and at the one year follow up. Sleep deprivation, hyperventilation, and photic stimulation were used as activating procedures. A total of 170 preoperative EEGs (mean 5.3 recordings per patient) were reviewed. Interictal epileptiform discharges (spikes, sharp waves, and spike and wave complexes) were analysed according to the criteria of Gloor ${ }^{14}$ and are referred to here as "spikes". If focal slow wave activity of neocortical, or mesial temporal, or both locations was present, both intermittent and continuous foci of polymorphic theta delta activity were included. Spikes and slow wave activity were further analysed with respect to the epileptic focus; either temporal, or extratemporal locations, or both with respect to the side of the resected lobe, were linked in the following way: (1) the abnormalities that existed ipsilateral to the resected side formed the unilateral group; (2) the bilateral group consisted of both contralateral and bilateral abnormalities. If any of the recordings in each patient showed bilateral findings it was interpreted as bilateral. Postoperatively at one year the EEGs (sphenoidal EEG and sleep deprived EEG with sphenoidal electrodes, two recordings per patient) were analysed similarly to the preoperative EEGs.

\section{NEUROPSYCHOLOGICAL ASSESSMENT}

To examine cognitive as well as verbal and visual memory functions, neuropsychological evaluation was made preoperatively and postoperatively at two weeks and at one year after surgery for all patients. Preoperative and one year postoperative results were evaluated. Hemispheral dominance for speech was determined in all patients before operation by the intracarotid sodium amylobarbitone procedure (Wada test), as described by Milner. ${ }^{6}$ Although none of the patients were right hemisphere dominant, we excluded the data of two with bilateral speech representation from further neuropsychological analyses.

Cognitive functions were tested by the Wechsler adult intelligence scale (WAIS) ${ }^{15}$ and memory by the Wechsler memory scale (WMS). ${ }^{16}$ Verbal and visual memory functions were evaluated by delayed memory tests. ${ }^{6}$ In the delayed verbal test the function of the dominant hemisphere was evaluated, and the score was the combined sum of the delayed recall scores of two verbal subtestsnamely, WMS stories (logical memory) and paired associate learning. The delayed visual tests were used to assess non-dominant hemisphere function and the scores were delayed recall of the non-verbal test of WMS (visual reproduction) and Rey's complex figure test. ${ }^{17} 18$ The delayed responses for these tests were asked for after a 45 minute period of 
distraction, which was filled with other psychometric tests. Immediate memory scores were determined in the same way; in the associate learning test the immediate score was the number of words recalled correctly in the third trial.

Verbal skills were tested by the object naming test ${ }^{19}$ and by the token test. ${ }^{20}$ Motor speed was determined by the finger tapping test, ${ }^{21}$ in which the score was the mean of both hands determined as the mean of three trials of 10 seconds each. Frontal functioning was also tested; in the modified version of the Chicago word fluency test ${ }^{22}$ the patient was asked to write as many different words as possible beginning with $S$ in five minutes (part $I$ ) and as many four letter words beginning with $\mathrm{K}$ in four minutes (part II). The final scores were the separate scores for both parts of this test, and the sum value of the total test was also determined. The Wisconsin card sorting test ${ }^{23}$ was used in its standardised form. Finally, a neuropsychological binomial classification of lateralisation was determined by categorising the patients into unilateral and bilateralcontralateral subgroups according to their preoperative results in the lateralising tests.

\section{PSYCHIATRIC ASSESSMENT}

A standardised psychiatric interview questionnaire ${ }^{24}$ was used by experienced psychiatrists to evaluate the psychiatric status of the patients. To exclude psychiatric contraindications for surgery, psychiatric assessment was scheduled preoperatively for every patient. Postoperatively, the patients were interviewed at every follow up (two weeks, three months, and one year) with procedures similar to that used before surgery. At the one year follow up, data for 29 patients were available. If the patients showed any significant psychiatric symptoms at follow up interviews, they were diagnosed according to the DSM-III-R criteria and extra follow up visits and psychiatric drug treatment were scheduled. In this study, however, only the data obtained by questionnaire were evaluated.

The questionnaire used consisted of 22 ratings, 10 ratings of symptoms reported by the patient, and 12 ratings of abnormalities manifest at the interview. The patients were evaluated and rated on the basis of a five point response scale $(0=$ absent to $4=$ severe).

Table 1 Composition of psychopathology scores made on the basis of the standardised psychiatric interview

\begin{tabular}{|c|c|c|}
\hline Variable & Reported symptoms & Manifest abnormalities \\
\hline Somatisation & $\begin{array}{l}\text { Somatic symptoms } \\
\text { Fatigue }\end{array}$ & $\begin{array}{l}\text { Excessive concern with bodily } \\
\text { functions }\end{array}$ \\
\hline Mood & $\begin{array}{l}\text { Sleep disturbance } \\
\text { Lack of concentration } \\
\text { Depression }\end{array}$ & $\begin{array}{l}\text { Slow, lacking spontaneity } \\
\text { Depressed } \\
\text { Depressive thought content } \\
\text { Elated, euphoric }\end{array}$ \\
\hline Anxiety & $\begin{array}{l}\text { Irritability } \\
\text { Anxiety } \\
\text { Phobias } \\
\text { Obsessions and compulsions } \\
\text { Depersonalisation }\end{array}$ & $\begin{array}{l}\text { Histrionic } \\
\text { Anxious, agitated, tense }\end{array}$ \\
\hline Psychotic symptoms & & $\begin{array}{l}\text { Suspicious, defensive } \\
\text { Flattened, incongruous } \\
\text { Thought disorder, delusions, } \\
\text { misinterpretations } \\
\text { Hallucinations }\end{array}$ \\
\hline Intellectuality & & Intellectual impairment \\
\hline
\end{tabular}

A total score consisting of all the ratings was determined for every patient at each follow up. Based on this total score, the patients were divided into the following groups: (a) asymptomatic (scores of 3 or below), (b) minor symptoms (scores of 4 to 9 ), and (c) major symptoms (scores of 10 or above). Also, in the analysis of psychiatric outcome, a binomial classification between asymptomatic patients (group 1) and symptomatic patients (groups 2 and 3) was made (threshold 3/4). Based on the ratings, the following psychopathological variables were also determined: somatisation, mood, anxiety, psychotic symptoms, and intellectuality (table 1). For each variable, the mean score (the sum of the scores divided by the number of ratings) was determined and used for further comparisons.

\section{DATA ANALYSIS}

The dependence between two qualitative variables was tested by $\chi^{2}$ test or by Fisher's exact test. For evaluation of longitudinal changes, the difference (one year postoperativepreoperative) between the scores for each neuropsychological test was calculated, and it was tested by Student's $t$ test for paired samples. For the analyses between the groups, Student's $t$ test for independent samples was used. Non-parametric tests (Wilcoxon matched pairs signed ranks test and MannWhitney $U$ test) were chosen when the data did not meet the assumptions for normal distribution.

\section{Results}

CLINICAL OUTCOME AND EEG FINDINGS

Two weeks postoperatively, 27 patients $(85 \%)$ were seizure free, whereas five patients $(15 \%)$ exhibited seizures. At three months, 22 patients $(68 \%)$ and at one year 17 patients $(53 \%)$ were seizure free.

Preoperatively, interictal spikes in routine EEG were recorded for 25 patients (78\%); they were located unilaterally in 14 patients and bilaterally in 11. Non-epileptiform focal slow wave activity was found preoperatively in all patients. In 12 patients it was unilateral and in 20 patients it was bilateral. Postoperatively at the one year follow up the spikes were still seen in the recordings of seven patients $(22 \%)$, ipsilaterally in three patients, and contralaterally in four. Slow wave activity was found postoperatively in 29 patients $(91 \%)$, but it was bilateral in only 11 . Division of the patients into unilateral and bilateral groups according to preoperative EEG abnormalities showed that neither preoperative spikes nor preoperative slow wave activity in EEG were significantly associated with clinical outcome at one year postoperative follow up. Postoperative EEG showed that unilateral slow wave activity was seen mainly in seizure free patients and bilateral activity in those still exhibiting seizures, although this association was not significant. As only seven patients exhibited spikes in their postoperative EEGs, statistical analysis on the location of postoperative spikes was not possible. 
Table 2 Means (SD) for preoperative and one year postoperative scores on the neuropsychological tests in patient groups with resection of the left and right temporal lobe

\begin{tabular}{|c|c|c|c|c|c|}
\hline \multirow[b]{2}{*}{ Test variable } & \multirow{2}{*}{$\begin{array}{l}\text { No of patients } \\
\text { left/right }\end{array}$} & \multicolumn{2}{|l|}{ Left temporal } & \multicolumn{2}{|l|}{ Right temporal } \\
\hline & & Preoperative & Postoperative & Preoperative & Postoperative \\
\hline $\begin{array}{l}\text { WAIS full scale IQ } \\
\text { WAIS verbal IQ } \\
\text { WAIS performance IQ } \\
\text { WMS MQ }\end{array}$ & $\begin{array}{l}12 / 18 \\
12 / 18 \\
12 / 18 \\
12 / 18\end{array}$ & $\begin{array}{r}98.4(13 \cdot 2) \\
93.8(14 \cdot 2) \\
104 \cdot 3(12.9) \\
99.8(12.4)\end{array}$ & $\begin{array}{r}99.7(12.5) \\
94.3(15 \cdot 2) \\
106.5(13.5) \\
99.6(10.2)\end{array}$ & $\begin{array}{r}101.9(13.4) \\
99.4(12.7) \\
104.4(14 \cdot 8) \\
104.6(10.7)\end{array}$ & $\begin{array}{l}103.4(12.7) \\
101 \cdot 3(11.9) \\
104 \cdot 3(14.0) \\
106.5(11 \cdot 7)\end{array}$ \\
\hline $\begin{array}{l}\text { WMS verbal memory: } \\
\text { Immediate }\end{array}$ & & & & & \\
\hline $\begin{array}{l}\text { Immediate } \\
\text { Delayed } \\
\text { WMS visual memory: }\end{array}$ & $\begin{array}{l}12 / 18 \\
12 / 18\end{array}$ & $\begin{array}{l}16 \cdot 1(3 \cdot 3) \\
11 \cdot 7(3 \cdot 7)\end{array}$ & $\begin{array}{l}14 \cdot 8(2 \cdot 5) \\
11 \cdot 1(3 \cdot 7)\end{array}$ & $\begin{array}{l}17 \cdot 6(2 \cdot 2) \\
14 \cdot 8(2 \cdot 4)\end{array}$ & $\begin{array}{l}18 \cdot 1(3 \cdot 3) \\
15 \cdot 9(3 \cdot 4)\end{array}$ \\
\hline Immediate & $\begin{array}{l}12 / 18 \\
12 / 18\end{array}$ & $\begin{array}{r}11.4(2.2) \\
9.8(3.0)\end{array}$ & $\begin{array}{r}12 \cdot 4(1 \cdot 7) \\
8 \cdot 3(4 \cdot 1)\end{array}$ & $\begin{array}{r}10 \cdot 7(2 \cdot 5) \\
9 \cdot 6(2 \cdot 4)\end{array}$ & $\begin{array}{r}10 \cdot 2(2 \cdot 5) \\
8 \cdot 4(3 \cdot 3)\end{array}$ \\
\hline $\begin{array}{l}\text { Rey complex figure test: } \\
\text { Delayed } \\
\text { Object naming test } \\
\text { Token test } \\
\text { Finger tapping test } \\
\text { Chicago word fluency test } \\
\text { Part I } \\
\text { Part II } \\
\text { Wisconsin card sorting test }\end{array}$ & $\begin{array}{l}12 / 17 \\
12 / 17 \\
12 / 17 \\
11 / 16 \\
12 / 17 \\
12 / 17 \\
12 / 17 \\
10 / 11\end{array}$ & $\begin{array}{l}14 \cdot 6(4 \cdot 1) \\
18 \cdot 2(1 \cdot 9) \\
57 \cdot 9(2 \cdot 7) \\
45 \cdot 1(5 \cdot 2) \\
35 \cdot 6(13 \cdot 7) \\
22 \cdot 0(9 \cdot 2) \\
13 \cdot 6(5 \cdot 9) \\
3 \cdot 8(2 \cdot 1)\end{array}$ & $\begin{array}{l}15 \cdot 9(5 \cdot 8) \\
18 \cdot 8(2 \cdot 8) \\
58 \cdot 1(2 \cdot 7) \\
46 \cdot 5(4 \cdot 7) \\
39 \cdot 6(16 \cdot 7) \\
25 \cdot 8(10 \cdot 2) \\
13 \cdot 8(7 \cdot 8) \\
5 \cdot 4(1 \cdot 0)^{\star}\end{array}$ & $\begin{array}{l}13 \cdot 8(5 \cdot 9) \\
20 \cdot 4(3 \cdot 4) \\
59 \cdot 8(1 \cdot 9) \\
45 \cdot 7(6 \cdot 9) \\
42 \cdot 3(13 \cdot 6) \\
26 \cdot 2(8 \cdot 3) \\
16 \cdot 1(6 \cdot 2) \\
3 \cdot 8(1 \cdot 7)\end{array}$ & $\begin{array}{l}12 \cdot 7(6 \cdot 2) \\
20 \cdot 7(3 \cdot 1) \\
60 \cdot 0(2 \cdot 4) \\
46 \cdot 2(7 \cdot 5) \\
46 \cdot 9(15 \cdot 9) \\
30 \cdot 9(8 \cdot 5)^{\star \star} \\
16 \cdot 0(8 \cdot 3) \\
3 \cdot 7(2 \cdot 5)\end{array}$ \\
\hline
\end{tabular}

${ }^{\star} \mathrm{P}<0.05 ;{ }^{\star \star} \mathrm{P}<0.01$, Student's $t$ test for paired samples.

WAIS = Wechsler adult intelligence scale; $I Q=$ intelligence quotient; WMS = Wechsler memory scale; $M Q=$ memory quotient.

Mean scores of the

psychopathology variables (according to ratings on the standardised

psychiatric interview)

during postoperative follow

up in seizure free patients and those still exhibiting

seizures. The mean scores were computed by adding together the scores for each variable and dividing the sum by the number of ratings. Postoperatively, affective symptoms (mood) improved in seizure free patients and were impaired in those who were not seizure free. ${ }^{*} P<0.05$, Mann-Whitney $U$ test, between groups at one year follow up.
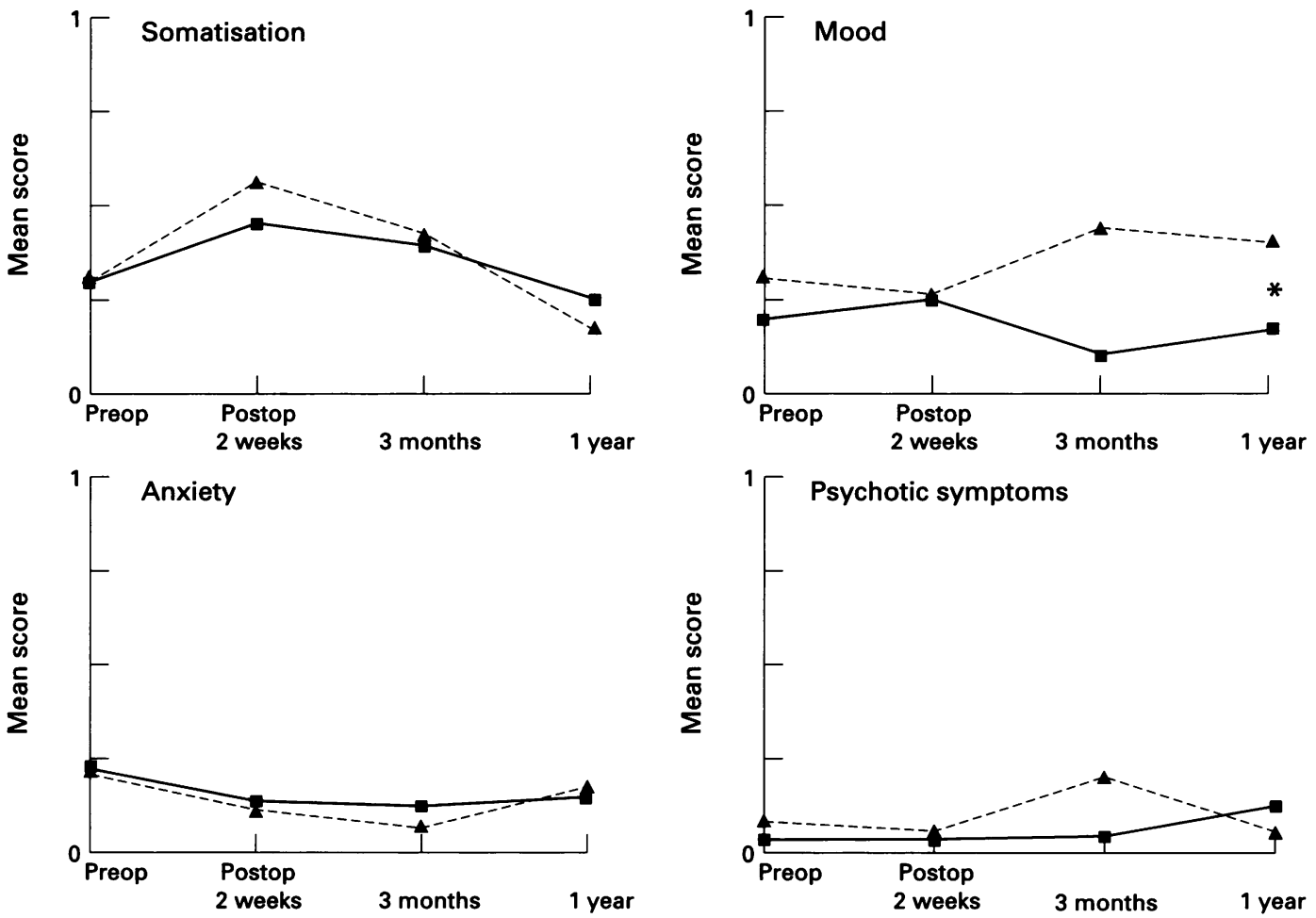

Seizure free

$\Delta$ Not seizure free

NEUROPSYCHOLOGICAL ASSESSMENT

Due to the material specific changes in memory tests, the scores were analysed according to the side of operation (table 2). In general, there was a tendency for memory scores to deteriorate on the side of resection and to improve on the non-resected side after surgery. Scores on the tests measuring frontal functions were also improved. In patients with surgery on the non-dominant hemisphere, significant improvement $(P<0.01)$ was seen in the Chicago word fluency test (subtest part I). In patients with dominant hemisphere resection, a parallel improvement was seen, although it was not statistically significant. In the more complex part of this test (part II), however, no improvement was found. In the other frontal test, the Wisconsin card sorting test, performance improved only in patients with surgery on the dominant side $(P<0.05)$.

PSYCHIATRIC ASSESSMENT

At one year postoperative follow up the affective symptoms of the patients (mood) differed significantly between patients with and those without seizures $(P<0.05)$; the mean scores improved in seizure free patients and were impaired in those who were not seizure free 
Table 3 Means (SD) for preoperative and one year postoperative scores on the delayed memory tests in patient groups with left and right temporal surgery and with unilateral and bilateral spikes and slow wave abnormalities in preoperative EEG

\begin{tabular}{|c|c|c|c|c|c|c|c|c|}
\hline \multirow{2}{*}{$\begin{array}{l}\text { Test } \\
\text { variable }\end{array}$} & \multirow{2}{*}{$\begin{array}{l}\text { Preoperative } \\
E E G\end{array}$} & \multirow{2}{*}{$\begin{array}{l}\text { No of patients } \\
\text { left/right }\end{array}$} & \multicolumn{2}{|l|}{ Left temporal } & \multirow{2}{*}{$\begin{array}{l}\text { Difference } \\
\text { value }\end{array}$} & \multicolumn{2}{|c|}{ Right temporal } & \multirow{2}{*}{$\begin{array}{l}\text { Difference } \\
\text { value }\end{array}$} \\
\hline & & & Preoperative & Postoperative & & Preoperative & Postoperative & \\
\hline \multicolumn{9}{|c|}{ Slow wave activity: } \\
\hline Delayed visual memory & $\begin{array}{l}\text { Unnilateral } \\
\text { Bilateral }\end{array}$ & $\begin{array}{l}5 / 6 \\
7 / 12\end{array}$ & $\begin{array}{l}12 \cdot 0(3 \cdot 1) \\
11 \cdot 4(4 \cdot 2)\end{array}$ & $\begin{array}{l}12 \cdot 2(2 \cdot 8) \\
10 \cdot 3(4 \cdot 2)\end{array}$ & $\begin{array}{l}0 \cdot 2(0 \cdot 8) \\
-1 \cdot 1(4 \cdot 7)\end{array}$ & $\begin{array}{l}15 \cdot 0(2 \cdot 0) \\
14.8(2 \cdot 6)\end{array}$ & $\begin{array}{l}17 \cdot 8(2 \cdot 1) \dagger \\
14.9(3 \cdot 6)\end{array}$ & $\begin{array}{l}2 \cdot 8(1 \cdot 3) \\
0 \cdot 2(2 \cdot 1)\end{array}$ \\
\hline \multicolumn{9}{|c|}{$\begin{array}{l}\text { Delayed visual memory: } \\
\qquad \begin{array}{l}\text { Unilateral } \\
\text { Bilateral }\end{array} \\
\text { Delayed verbal memory: }\end{array}$} \\
\hline Delayed visual memory & $\begin{array}{l}\text { Unilateral } \\
\text { Bilateral } \\
\text { : }\end{array}$ & $\begin{array}{l}8 / 12 \\
4 / 6\end{array}$ & $\begin{array}{l}12.5(3 \cdot 1) \\
10 \cdot 0(4 \cdot 6)\end{array}$ & $\begin{array}{l}11 \cdot 6(3 \cdot 1) \\
10 \cdot 0(4 \cdot 9)\end{array}$ & $\begin{array}{l}-0.9(2.3) \\
0.0(5 \cdot 9)\end{array}$ & $\begin{array}{l}15 \cdot 5(2 \cdot 2) \\
13 \cdot 5(2 \cdot 3)\end{array}$ & $\begin{array}{l}17 \cdot 2(1.9) \dagger \\
13 \cdot 3(4 \cdot 5)\end{array}$ & $\begin{array}{l}1 \cdot 7(2 \cdot 1) \\
-0 \cdot 2(2 \cdot 2)\end{array}$ \\
\hline & $\begin{array}{l}\text { Unilateral } \\
\text { Bilateral }\end{array}$ & $\begin{array}{l}8 / 12 \\
4 / 6 \\
\end{array}$ & $\begin{array}{r}10.4(3.0) \\
8.5(3 \cdot 1) \\
\end{array}$ & $\begin{array}{l}9 \cdot 8(3 \cdot 7) \\
5 \cdot 5(3 \cdot 7)\end{array}$ & $\begin{array}{l}-0.6(3.4) \\
-3.0(1.6)\end{array}$ & $\begin{array}{l}9 \cdot 7(2 \cdot 8) \\
9 \cdot 3(1 \cdot 6)\end{array}$ & $\begin{array}{l}9.6(3.3) \\
6.0(1.5) \dagger\end{array}$ & $\begin{array}{l}-0.1(3 \cdot 4) \\
-3 \cdot 3(2 \cdot 2)\end{array}$ 太 \\
\hline
\end{tabular}

${ }^{\star} \mathrm{P}<0.05 ;{ }^{\star \star} \mathrm{P}<0.01$, unilateral $v$ bilateral groups (Mann-Whitney $U$ test); $\dagger \mathrm{P}<0.05$, preoperative $v$ post operative groups (Wilcoxon's test)
Difference value $=$ one year postoperative score-preoperative score.

(figure). The number of patients without psychiatric problems increased after surgery; 14 of 32 patients $(44 \%)$ preoperatively and 17 of 29 patients $(59 \%)$ postoperatively at one year were rated as asymptomatic - that is, the total scores of standardised psychiatric interview were $\leqslant 3$. Thirteen out of 19 patients $(68 \%)$, who were rated as asymptomatic postoperatively at three months, remained asymptomatic at one year; minor symptoms appeared in five patients $(26 \%)$ and major symptoms in one patient $(5 \%)$ at one year after the asymptomatic three month follow up. For evaluation of the association between EEG abnormalities and psychiatric outcome, the patients were further divided into asymptomatic and symptomatic groups according to their psychiatric outcome at one year postoperative follow up. No significant association was found whether these patient groups exhibited seizures or not at one year, whether they showed unilateral or bilateral spikes or slow wave activity in preoperative EEGs, or whether the slow wave activity was unilateral or bilateral in postoperative EEGs.

\section{NEUROPSYCHOLOGICAL AND PSYCHIATRIC} CHANGES IN RELATION TO EEG AND CLINICAL OUTCOME

The presence and location of preoperative focal slow wave focus was associated with changes in the delayed memory scores of WMS subtests (table 3 ). The patients were further divided into two groups: those with dominant (left sided) and those with nondominant (right sided) hemisphere operation. In patients with left sided operation, the changes in delayed visual memory scores differed significantly between the two patient groups with unilateral or bilateral abnormalities in preoperative EEGs $(P<0.01)$; the scores improved in patients with unilateral slow wave focus, whereas they deteriorated in patients with bilateral focus. In patients with right sided operation, the delayed verbal memory scores of those with unilateral and bilateral focal slowing also differed significantly from each other $(P<0.05)$; these scores improved in patients with unilateral focus and remained unchanged in those with bilateral slow wave focus.
For evaluation of the relation between preoperative spikes and these memory scores, those patients without spikes in preoperative EEGs were placed in the unilateral group. The presence and location of preoperative spikes also showed a trend toward association with postoperative memory on the nonresected side, although these differences between unilateral and bilateral location of the spikes did not reach significance (table 3 ). On the other hand, the delayed visual memory had deteriorated significantly more, especially in patients with right sided operation and bilateral spikes compared with patients with unilateral spikes $(P<0.05)$.

Preoperative slow wave activity in EEG was significantly associated with the lateralising findings in preoperative neuropsychological test performance $(P<0.05)$. Those patients with unilateral preoperative slow wave activity in EEG had unilateral findings in preoperative neuropsychological testing, whereas patients with bilateral slow wave activity showed signs of bilateral neuropsychological findings in preoperative studies. Seizure free patients did not differ significantly from the rest of the patients in any of the neuropsychological tests. Changes in general intelligence scores were not related to preoperative slow wave activity in EEG.

The only neuropsychological test that was related to psychiatric outcome was the Chicago word fluency test. The scores for the whole test and especially those for part I improved significantly more in patients without psychiatric problems at one year follow up than in the rest of the group $(P<0.05)$.

\section{Discussion}

The presence and location of preoperative slow wave activity in EEG predicted improvement or deterioration in postoperative memory of the non-resected side. In patients with dominant hemisphere resection and unilateral slow wave activity in EEG on the side of the resected lobe, the delayed visual memory improved postoperatively. On the other hand, the delayed visual memory was impaired in those patients with dominant hemisphere 
resection and bilateral slow wave focus in preoperative EEG. Among patients with resection on the non-dominant hemisphere, the delayed verbal memory improved in those with unilateral slow wave focus and remained virtually unchanged in those with bilateral slow wave activity in preoperative EEG.

In routine EEG recordings, focal epileptiform and non-epileptiform abnormalities often coincide. In this study the effect of spikes as well as that of slow wave activity were analysed. For indicating postoperative memory disturbance on the non-resected side, the location of preoperative slow wave activity was more definite than the location of epileptiform activity. Thus postoperative memory performance could clearly be separated into two different groups according to preoperative non-epileptiform EEG. A release of function phenomenon (postoperative improvement of the hemispheric function contralateral to the resected lobe) has recently been suggested to be the result of practice effects. ${ }^{25}$ As improvement of delayed memory scores occurred in our study only in patients with unilateral slow wave focus but not in those with bilateral slowing, the practice effect seems an unlikely reason for these changes.

Barry et $a l^{2}$ showed that well defined localisation of temporal spikes in EEG predicts the most favourable clinical outcome after surgery. In our study no significant association was found between clinical outcome and unilateral or bilateral location of preoperative EEG abnormalities. By contrast with some reports summarised recently, ${ }^{26}$ the scores of our patients on the Chicago word fluency test, which measures frontal lobe functions, improved significantly postoperatively. This improvement was seen especially in the simpler part of the test (part I), and psychiatric status was related to the performance on this test-that is, in patients without psychiatric problems at one year follow up, the scores improved more. Another reason for the postoperative improvement in frontal lobe tests may be the improved functioning of other brain areas after removal of the epileptogenic lesion. ${ }^{6}$

The circuits between the mesial structures and the temporal neocortex are essential for memory functions. ${ }^{27} 28$ Our results indicate that a relation does exist between memory disturbances and focal slow wave activity in EEG, and thus the dysfunction within the structures responsible for lateralising memory tests also affects EEG. The presence and the location of the slow wave focus in preoperative EEGs seemed to predict postoperative memory functioning; those patients with unilateral slow wave focus scored significantly better on postoperative delayed memory tests contralateral to the resected lobe than did those with bilateral slow wave focus in preoperative routine EEG. Localised delta activity in routine EEG is believed to result from partial cortical deafferentation from subcortical inputs. ${ }^{29}$ In patients with partial epilepsy, slow wave activity is usually seen in a localised fashion, even without an underlying structural lesion $^{30}$; and it can reflect functional deficit in mesial temporal areas. ${ }^{31}$ One could hypothesise that in patients with temporal lobe epilepsy the non-epileptiform abnormalities on EEG over anterior temporal regions are modulated by the dysfunction within the mesial temporal structures, probably partly due to hippocampal atrophy. ${ }^{32}$

A wide variety of protocols are used in psychiatric evaluation for epilepsy surgery, and in some centres the general health questionnaire is used. ${ }^{1033}$ In interviewer analysis, its shorter version, the standardised psychiatric interview, has been found to be reliable. ${ }^{24} \mathrm{We}$ used this questionnaire in preoperative and postoperative evaluation of patients with temporal lobe surgery. According to these ratings, the seizure free patients exhibited significantly fewer affective symptoms postoperatively at the one year follow up than did the rest of the patients. Seizure free outcome has generally been linked with improvement in the psychiatric and psychosocial status of epileptic patients. ${ }^{73-35}$ Accordingly, transient depression has been reported to last for no longer than three months after operation. ${ }^{10}$ Our patients with psychiatric problems were seen more often beyond the scheduled follow up times and were treated with antidepressive drugs. Without effective psychiatric treatment, the difference in mood scores between the seizure free patients and those still exhibiting seizures might have been even greater. The number of psychiatrically asymptomatic patients was increased by $15 \%$ at the one year follow up compared with baseline ratings. We found that the additional evaluation of psychiatric status by numerical scoring is valuable for screening and follow up in epilepsy surgery; in addition, the standardised interview and scoring can guide the psychiatrist to a more detailed examination.

Interictal EEG plays a valuable part not only in preoperative evaluation of epileptogenic lesion but also in prediction of memory performance in patients after temporal lobectomy. Based on our findings on patients with intractable and longstanding epilepsy, we conclude that successful outcome in postoperative memory functioning after operation is achieved in patients with unilateral slow wave activity in preoperative EEG.

This study was supported by a research grant from the University of Kuopio. We thank Dr Eeva-Liisa Helkala and Dr Asla Pitkänen for comments on the manuscript, and Pirjo Halonen for statistical advice.

1 Bengzon ARA, Rasmussen $T$, Gloor $P$, Dussault $J$, Stephens M. Prognostic factors in the surgical treatmen of temporal lobe epileptics. Neurology 1968;18:717-31.

2 Barry E, Sussman NM, O'Connor MJ, Harner RN. Presurgical electroencephalographic patterns and outcome from anterior temporal lobectomy. Arch Neuro 1992;49:21-7.

3 Engel J Jr, Driver MV, Falconer MA. Electrophysiological correlates of pathology and surgical results in temporal lobe epilepsy. Brain 1975;98:129-56.

4 Lieb JP, Engel J Jr, Gevins A, Crandall PH. Surface and deep EEG correlates of surgical outcome in temporal lobe epilepsy. Epilepsia 1981;22:515-38.

5 So N, Olivier A, Andermann F, Gloor P, Quesney LF Results of surgical treatment in patients with bitemporal pileptiform abnormalities. Ann Neurol 1989;25:432-9.

6 Milner B. Psychological aspects of focal epilepsy and its neurosurgical management. In: Purpura DP, Penry JK Walter RD, eds. Advances in neurology. Vol 8, New York: Raven Press, 1975:299-321. 
7 Rausch R, Crandall PH. Psychological status related to surgical control of temporal lobe seizures. Epilepsia 1982;23:191-202.

8 Novelly RA, Augustine EA, Mattson RH, et al. Selective memory improvement and impairment in temporal lobectomy for epilepsy. Ann Neurol 1984;15:64-7.

9 Jones-Gotman M. Localization of lesions by neuropsychological testing. Epilepsia 1991;32(suppl 5):S41-52.

10 Fenwick P. Long-term psychiatric outcome after epilepsy surgery. In: Lüders H, ed. Epilepsy surgery. New York: Raven Press, 1991:647-52.

11 Nousiainen U, Suomalainen T, Mervaala E. Clinical benefits of scalp EEG studies in intractable seizure disorders. Acta Neurol Scand 1992;85:181-6.

12 Engel J Jr. Outcome with respect to epileptic seizures. In: Engel J Jr, ed. Surgical treatment of the epilepsies. New York: Raven Press, 1987:553-71.

13 King DW, So EL, Marcus R, Gallagher BB. Techniques and applications of sphenoidal recording. $f$ Clin and applications of sph

14 Gloor P. Contributions of electroencephalography and electrocorticography to the neurosurgical treatment of the epilepsies. In: Purpura DP, Penry JK, Walter RD, eds. Advances in neurology. Vol 8. New York: Raven Press, 1975:59-105.

15 Wechsler D. Wechsler adult intelligence scale. Manual. New York: Psychological Corporation, 1955.

16 Wechsler D. A standardized memory scale for clinical use. f Psychol 1945;19:87-95.

17 Rey A. L'examen psychologique dans les cas d'encéphalopathie traumatique. Arch Psychol 1941;28: 286-340.

18 Osterrieth PA. Le test de copie d'une figure complexe. Arch Psychol 1944;30:206-356.

19 Newcombe F. Missile wounds of the brain: a study of psychological deficits. London: Oxford University Press, 1969.

20 Boller F, Vignolo LA. Latent sensory aphasia in hemisphere-damaged patients: an experimental study with sphere-damaged patients: an experi

21 Lezak MD. Neuropsychological assessment. New York: Oxford University Press, 1983.
22 Thurstone LL, Thurstone TG. The Chicago tests of primary mental abilities. Chicago: Science Research Associates, 1943

23 Grant DA, Berg EA. A behavioral analysis of degree of reinforcement and ease of shifting to new responses in a Weigl-type card-sorting problem. F Exp Psychol 1948, 38:404-11.

24 Goldberg DP. The detection of psychiatric illness by questionnaire. London: Oxford University Press 1972:63-83.

25 Awad IA, Chelune GJ. Outcome and complications. In Wyllie E, ed. The treatment of epilepsy: principles and practice. Philadelphia: Lea and Febiger, 1993:1084-91.

26 Chelune GJ. Using neuropsychological data to forecast postsurgical cognitive outcome. In: Lüders $\mathrm{H}$, ed. Epilepsy surgery. New York: Raven Press, 1991:477-85.

27 Milner B. Hippocampal-neocortical interaction in human memory processes. In: Squire LR, Mishkin $M$, Shimamura A, eds. Learning and memory. Discussions in neuroscience, VI. Amsterdam: Elsevier, 1990:101-8.

28 Squire LR, Zola-Morgan S. The medial temporal lobe memory system. Science 1991;253:1380-6.

29 Gloor P, Ball G, Schaul N. Brain lesions that produce delta waves in the EEG. Neurology 1977;27:326-33.

30 Marshall DW, Brey RL, Morse MW. Focal and/or lateralized polymorphic delta activity. Arch Neurol 1988;45:33-5.

31 Engel J Jr. Recent advances in surgical treatment of temporal lobe epilepsy. Acta Neurol Scand 1992;86(supp 140):71-80

32 Gambardella A, Cendes F, Gotman J, Andermann F Scalp EEG abnormalities in patients with unilatera hippocampal atrophy. Neurology 1993;43:A160.

33 Hermann BP, Wyler AR, Somes G. Preoperative psychological adjustment and surgical outcome are determinants of psychosocial status after anterior temporal lobectomy. F Neurol Neurosurg Psychiatry 1992;55:491-6.

34 Taylor DC, Falconer MA. Clinical, socio-economic, and psychological changes after temporal lobectomy for psychological changes after temporal lo
epilepsy. Br f Psychiatry 1968;114:1247-61.

35 Hermann BP, Wyler AR. Depression, locus of control, and the effects of epilepsy surgery. Epilepsia 1989;30:332-8.

\section{Charcot joints}

Tabes dorsalis is now an uncommon disease in Western countries, but patients with Argyll Robertson pupils and Charcot joints are frequently dredged up to appear in clinical examinations. Arthropathy of ataxic patients, Charcot's original description, ${ }^{1}$ was passed on to his students in a model lecture. ${ }^{2} \mathrm{He}$ summarises the salient points:

"A. Without appreciable external cause,...the local affection appears. At this moment the incoordination is not marked, the patients do not fling about their legs in a disorderly manner.

B. This arthropathy is developed at a but slightly advanced period of the spinal disease, and most commonly when its symptomatology is limited to lightning pains....

C. The arthropathy is produced, generally, without prodromes, if we except, however those cracking sounds [in the joint] which we find...

$E^{\star}$. Most usually, the first phenomenon discernible is extreme tumefaction of the entire member... formed $1^{\circ}$, by a considerable hydrarthrosis; $2^{\circ}$, by an engorgement which,...presents a hard consistence, and in which the ordinary symptoms of oedema are not generally very marked."

"This arthropathy is not commonly accompanied by fever, or by pains;...

At the end of some weeks or months, the swelling disappears and then all returns to the normal state (benignant form); sometimes, on the contrary, serious disorders remain in the joints, crackings, dislocations, answering to a wearing down of the osseous surfaces, and various luxations (malignant form). The member affected by arthropathy may still serve for prehension, if it be the upper extremity; or for walking, if the hip and knee be... affected. F. ...the order of preference begins with the knee, then comes the shoulder, next the elbow, the hips, and the wrists. But the small articulations are not always spared..."

Charcot separates the condition from osteoarthritis (dry arthritis), purulent arthritis, and nodose rheumatism and from gout. Pathologically: "in cases of old standing...the signs observed are those of dry arthritis: to whit, eburnation and deformation of the articular surfaces...bony burrs and stalactites, foreign bodies etc....I must request your attention to: $1^{\circ}$. The predominance of wearing away over the production of bony burrs in recent cases..., $2^{\circ}$. ...the frequency of luxations, which are, to some extent, the rule in ataxic arthropathy...while they are only exceptions in common dry arthritis..."

Seeking enlightenment as to the cause, he finds analogies in the arthropathies of paraplegia in Pott's disease, acute myelitis, tumours of gray substance, and traumatic spinal lesions. Charcot concludes that the anterior cornua of the gray matter, and in one case the spinal ganglia, are the starting point of the articular disorder.

The great English physician Thomas Clifford Albutt recognised, and described ${ }^{3}$ the same clinical features a year later.

J M S PEV PEARCE Anlaby, Hull HU10 7BG, UK

* the item "D" is omitted (presumably a typographical error) in the original text.

1 Charcot JM. Sur quelques arthropathies qui parnessent dépendre d'une lésion du cerveau ou de la moëlle épinière. Archives Physicale Normal Pathologie 1868;1 161-78

2 Charcot JM. On some visceral derangements in locomotor ataxia. Arthropathies of ataxic patients. In: Lectures on the disease of the nervous system. 2nd series. Translated by George Sigerson. London: The New Sydenham Society, 1881:53-61.

3 Albutt TC. Remarks on a case of locomotor ataxy with hydrarthrosis. St George's Hospital Reports 1869; 4:259-60. 